\title{
Analisis Break Even Point Budidaya Bunga Potong Krisan Di Kelurahan Kakaskasen 1 Kota Tomohon (Studi Kasus Kelompok Tani KIBERTA)
}

\author{
Boyke Jansen Gosal \\ Noortje M. Benu \\ Celcius Talumingan
}

\begin{abstract}
The objective of this research is to calculate the Break Even Point (BEP), which is an approach to analyze production volume planning and increasing business prospect. This research was carried out from June to July 2016. Data used in this research was primary data that obtained from interview and secondary data obtained from related agencies and journals to support this research. Data analysis used Break Even Point analysis, which is to analyze the business's break even point in both rupiah and unit. KIBERTA farmer group has a directly Marketing channel with the buyers that directly come to KIBERTA's greenhouse. Chrysanthemum stalk flower cultivation in this farmers carried out in one greenhouse per period in turns, by order with 6 weeks gap in planting between greenhouses and farmers harvesting once in three weeks with four total of greenhouses which is in size $10 \times 25 \mathrm{~m}^{2}, 20 \times 25 \mathrm{~m}^{2}, 8 \times 14 \mathrm{~m}^{2}$, and $8 \times 15 \mathrm{~m}^{2}$. This farmers sell Rp. 3000, - per stalk in all type and colors. The research result shows that from 100\% which is planted only $70 \%$ were able to be harvest / within selling requirement and based on analysis results from table and graphs found out that KIBERTA farmers' chrysanthemum stalk flower cultivation from revenue (Rupiah) and production (unit), exceed the Break Even Point and able to gain profits in all greenhouses *jnkd*.
\end{abstract}

Keywords: the Break Even Point, Chrysanthemum stalk flower cultivation, Kiberta farmer group, Tomohon City

\section{ABSTRAK}

Tujuan penelitian untuk untuk menghitung Break even point (BEP), yang mana pendekatan yang dapat dilakukan untuk menganalisis perencanaan volume produksi dan prospek peningkatan usaha. Penelitian dilaksanakan pada bulan April sampai bulan Juni 2016. Data yang digunakan dalam penelitian ini adalah data primer yang diperoleh melalui wawancara dan data sekunder yang diperoleh instansi dan jurnal terkait untuk mendukung penelitian ini. Analisis data yang digunakan analisis Break Even Point yang mana untuk menganalisis titik impas dalam rupiah dan unit. Kelompok Tani KIBERTA memiliki saluran pemasaran secara langsung dengan pembeli yang datang langsung ke greenhouse KIBERTA. Budidaya krisan potong di kelompok tani ini dilakukan disatu greenhouse per periode secara bergantian dengan jarak 6 minggu penanaman antara greenhouse dan kelompok tani ini memanen tiga minggu sekali dengan total 4 greenhouse yaitu ukuran $10 \times 25 \mathrm{~m}^{2}, 20 \times 25 \mathrm{~m}^{2}, 8 \times 14 \mathrm{~m}^{2}$, and $8 \times 15 \mathrm{~m}^{2}$. Kelompok tani ini menjual denga per tangkai Rp. 3000,- disemua tipe dan warna. Hasil penelitian menunjukan bahwa dari $100 \%$ yang ditanam hanya $70 \%$ yang memenuhi syarat panen dan jual, berdasarkan hasil analisis dari tabel dan grafik diketahui bahwa Budidaya Bunga Potong Krisan Kelompok Tani KIBERTA dari sisi penerimaan dan produksinya telah melampaui break even point dan dapat memperoleh keuntungan disemua greenhouse.

Kata kunci: Titik Impas, budidaya bunga potong Krisan, Kelompok tani Kiberta, Kota Tomohon

PENDAHULUAN

\section{Latar Belakang}

Pertanian memiliki peranan yang penting bagi perekonomian Indonesia. Pertanian berperan sebagai sumber ketahanan pangan, penyerap angkatan kerja, dan sebagai sumber devisa negara. Sektor pertanian memiliki peran strategis dalam pembangunan nasional. Mata pencaharian utama masyarakat Indonesia pada periode yang sama adalah bertani. Selama periode 2010-2015, sektor pertanian masih 
merupakan sektor dengan pangsa penyerapan tenaga kerja terbesar, walaupunada kecenderungan menurun. Sebagian besardari masyarakat Indonesia menggantungkan hidupnya dari sektor agraris ini, baik dalam bentuk sawah, ladang, kebun, atau yang lebih luas lagi dengan beternak, mencari hasil hutan, serta sektor perikanan baik laut maupun air tawar sehingga memiliki penyerapan tenaga kerja yang tinggi (Setyanti, 2016). Departemen Tenaga Kerja dan Transmigrasi mencatat pada tahun 2015 sektor pertanian menyerap sekitar 40 persen atau sebesar 40.122.816 jiwa dari seluruh angkatan kerja di Indonesia.

Subsektor hortikultura sebagai bagian dari sektor pertanian yang dapat dijadikan sumber pertumbuhan ekonomi Indonesia dimasa yang akan datang mengingat potensi sumber daya manusia, ketersediaan teknologi, serta potensi serapan pasar dalam negeri dan pasar internasional yang terus meningkat (Butaflika, 2008). Salah satu tanaman hortikultura yang memiliki nilai ekonomi tinggi adalah tanaman bunga (floriculture). Tingginya kebutuhan masyarakat untuk menggunakan bunga potong dalam berbagai kesempatan atau sebagai dekorasi, meningkatkan permintaan bunga dan potensi pengembangan usahatani (Setyanti, 2016).

Bunga krisan merupakan tanaman hias yang populer. Krisan mempunyai peluang besar untuk dapat meningkatkan taraf hidup petani karena tanaman tersebut memiliki nilai ekonomi tinggi dan mampu ditanam sepanjang tahun selama ketersediaan air mencukupi untuk budidaya (Sumarno, 2009). Pertumbuhan produksi krisan per tahun periode tahun 20102014 menurut Menteri Pertanian dalam Rencana Strategis Kementrian Pertanian 20152019 menempati urutan ketiga tertinggi sebesar $12,26 \%$ per tahun, tertinggi pada komoditas manga yaitu sebesar $21,95 \%$ per tahun, dan disusul manggis sebesar $13,82 \%$. Tingginya petumbuhan produksi krisan memiliki potensi dalam penyerapan tenaga kerja dan pengembangan usaha tani yang berdampak pada petumbuhan ekonomi negara.

Kota Tomohon atau dijuluki Kota Bunga adalah kota di Provinsi Sulawesi Utara yang memiliki budaya bunga dan mempunyai potensi dalam mengembangkan florikultura melalui even internasional yang diikuti berbagai negara. Produksi bunga potong (Bunga Krisan) di Kota Tomohon kelurahan kakaskasen merupakan pemasok utama bunga potong di Sulawesi utara. Hal ini dapat di lihat, menurut Dirjen hortikultura pada tahun 2012 Kota Tomohon menyumbang 598.078 dari total 661.247 produksi Krisan tangkai provinsi Sulawesi Utara. Berdasarkan data tersebut krisan merupakan komoditi unggulan dan peranan yang sangat penting bagi petani yang mengusahakannya dan Kota Tomohon sebagai kota bunga.

Kelompok tani sebagai bagian integral pembangunan pertanian memiliki peran dan fungsi penting dalam menggerakkan pembangunan pertanian disuatu daerah (Hermanto, 2011). Kelompok tani mempunyai peran penting untuk petani secara individu, salah satu contoh adalah dalam peringanan modal atau biaya produksi. Kelompok tani yang sudah terbentuk ini perlu untuk dibenahi dan diberdayakan sehingga mempunyai keberdayaan dalam melaksanakan usahataninya. Kelompok tani KIBERTA merupakan salah satu kelompok tani yang bersaing dengan kelompok tani lainya yang ada di Kota Tomohon.

Kelompok tani KIBERTA dibentuk pada tahun 2009, hingga saat ini memiliki 7 petani anggota aktif. Budidaya krisan potong kelompok tani KIBERTA dilakukan dalam greenhouse yang sama dan penjualan dilakukan dengan buyer/ pembeli datang langsung ke greenhouse. Kelompok tani KIBERTA memiliki empat greenhouse dan menurut Dinas Pertanian, Perkebunan, Perternakan dan Perikanan kota Tomohon dalam wawancara langsung kelompok tani ini merupakan salah satu dari empat kelompok tani yang dapat memproduksi bunga krisan terbanyak dari total 30 kelompok tani krisan yang terdaftar.

Perkembangan dan kemajuan dunia telah menimbulkan persaingan yang semakin ketat, sedangkan upaya untuk memperoleh keuntungan tidak dapat dipisahkan dari masalah penjualan (Hutani, 2015). Tomohon International Flower Festival (TIFF) yang akan diselenggarakan pada bulan Agustus 2016 merupakan peluang untuk petani bunga krisan, yang mana menurut Dinas Pertanian, 
Perkebunan, Perternakan dan Perikanan kota Tomohon bunga yang digunakan dalam parade adalah Aster dan Krisan maka pembelian bunga tersebut dilakukan oleh pemerintah kota secara besar-besaran. Peneliti juga mendapati bahwa dalam penjualan, bunga potong krisan kelompok tani KIBERTA selalu terjual habis, ini merupakan kesempatan peningkatan kapasitas usaha. Pendekatan yang dapat dilakukan untuk menganalisis perencanaan volume produksi dan prospek peningkatan usaha budidaya krisan potong ini adalah dengan melakukan analisis "break even point".

Analisis Break Even Point (BEP) ini dapat digunakan untuk mengetahui apakah suatu usaha menguntungkan atau merugikan dan dapat digunakan untuk menentukan skala usaha serta penetapan harga produk yang tepat agar petani tidak mengalami kerugian (Nuraga, 2015). Break even point (BEP) menganalisis hubungan antara biaya produksi, penerimaan dan volume produksi dan diartikan sebagai suatu titik atau keadaan dimana perusahaan di dalam operasinya tidak memperoleh keuntungan dan tidak menderita kerugian, dengan kata lain, pada keadaan itu keuntungan atau kerugian sama dengan nol (Munawir, 2002). Kelompok tani KIBERTA tidak memiliki pencatatan usaha yang merupakan hal penting dalam analisis break even point.

\section{Rumusan Masalah}

Berdasarkan latar belakang peneliti ingin mengetahui data penjualan, data biaya tetap, data biaya variable, dan harga jual serta data volume produksi yang diperlukan dalam analisis break even point, maka disusunlah rumusan masalah sebagai berikut:

1. Bagaimana data penjualan, data biaya tetap, data biaya variable, harga jual dan data volume produksi usaha budidaya bunga krisan kelompok tani KIBERTA ?

2. Apakah besarnya penerimaan dan produksi usaha budidaya bunga krisan kelompok tani KIBERTA telah mencapai Break even point ?

\section{Tujuan Penelitian}

Penelitian ini memiliki tujuan:

1. Untuk mengetahui data penjualan, data biaya tetap, data biaya variabel, harga jual dan data volume produksi.
2. Untuk mengetahui Break even point (BEP) dalam Penerimaan dan Produksi dalam budidaya bunga krisan potong di kelompok tani "KIBERTA".

\section{Manfaat Penelitian}

Manfaat yang dapat diperoleh dari penelitian ini:

1. Bagi kelompok tani KIBERTA, memberikan informasi kepada pengambil keputusan dalam peningkatan kapasitas usaha.

2. Bagi Pembaca, memberikan informasi tentang analisis Break even point budidaya bunga hias krisan potong di kelompok tani KIBERTA

Bagi peneliti, sebagai salah satu syarat untuk memperoleh gelar Sarjana Pertanian di

Universitas Sam Ratulangi Fakultas Pertanian.

\section{METODOLOGI PENELITIAN}

\section{Waktu dan Tempat Penelitian}

Penelitian ini berlangsung selama dua bulan Juni sampai Juli 2016. Lokasi penelitian dipilih secara sengaja (purposive), yaitu di Kelurahan Kakaskasen, Tomohon.

\section{Metode Pengumpulan Data}

Metode penelitian yang digunakan adalah studi kasus pada kelompok tani KIBERTA. Pengumpulan data dilakukan dengan menggunakan data primer yang diperoleh melalui wawancara langsung dengan kelompok tani tersebut dengan kuisioner. Data yang digunakan yaitu data kelompok tani KIBERTA selama satu periode produksi bunga krisan yaitu dari penanaman sampai panen selama tiga bulan ditahun 2016 .

\section{Konsep Pengukuran Variabel}

Data yang digunakan dalam penelitian ini adalah data satu periode produksi diempat greenhouse berbeda. Variabel-variabel yang diukur dalam penelitian ini :

1. Volume produksi (Tangkai)

Jumlah produksi bunga krisan satu kali produksi.

2. Total Penerimaan (Rp) 
Hasil penjualan yang diperoleh kelompok tani KIBERTA dari satu kali produksi bunga krisan.

3. Harga Jual (Rp/tangkai)

Harga jual krisan potong per tangkai

4. Biaya produksi yaitu biaya tetap dan biaya variable selama satu kali produksi.

a. Biaya Tetap

- Biaya penyusutan alat (Rp)

Biaya yang harus dikeluarkan karena terjadinya penurunan nilai dari peralatan yang digunakan.

- Biaya Penyusutan Greenhouse (Rp)

Biaya dari penyusutan Greenhouse yang digunakan untuk budidaya bunga potong krisan.

- Biaya Sewa Tanah (Rp)

Biaya yang dibayarkan untuk sewa tanah yang digunakan untuk greenhouse dan tempat bersangkutan dengan budidaya.

b. Biaya Variabel

- Biaya Bahan Baku (Rp/periode)

Biaya bibit, pupuk, pembasmi hama, dan listrik dalam budidaya Bunga potong krisan.

- Biaya Bahan Bakar (Rp/periode)

Biaya Bahan bakar yang digunakan untuk traktor dan motor kelompok tani KIBERTA

- Biaya Tenaga Kerja (Rp/periode)

Biaya yang dikeluarkan kelompok tani dalam pengolahan tanah, Persemaian, Penanaman, Pemupukan, Pemeliharaan, Pemberantasan hama dan Panen

\section{Teknik Analisis Data}

Analisis data yang digunakan adalah analisis Break even point (BEP). Perhitungan biaya tetap dalam penelitian ini dihitung dari biaya penyusutan Greenhouse dan peralatan yang digunakan dengan rumus (1) penyusutan (Baridwan dalam Bawinto, 2015) lalu dibagi per satu periode produksi:

Penyusutan per Tahun $=$ Nilai Beli-Nilai Sisa Umur Pakai

Analisis Break even point (BEP) digunakan untuk mengetahui hubungan antara variabel didalam kegiatan perusahaan yakni biaya produksi, volume produksi dan keuntungan yang diperoleh perusahaan. Rumus
BEP secara matematis yang digunakan (Riyanto dalam Bawinto, 2016):

Untuk Mengetahui BEP dalam Rp adalah sebagai berikut (2):

$$
\begin{aligned}
& \operatorname{BEP}(\text { Penerimaan } / \mathrm{Rp})= \\
& \text { Biaya Tetap } \\
& \frac{\text { Biaya Variabel per unit }}{\text { Harga per Unit }}
\end{aligned}
$$

Untuk mengetahui BEP dalam Unit adalah sebagai berikut (3):

BEP (Jumlah/Unit) $=$
$\frac{\text { Biaya Tetap }}{\text { Harga per Unit-Biaya Variabel per Unit }}$.

\section{HASIL DAN PEMBAHASAN}

\section{Deskripsi Umum Kelompok Tani KIBERTA}

Kelurahan Kakaskasen 1 merupakan salah satu kelurahan yang berada di Kecamatan Tomohon Utara yang merupakan sentra produksi bunga krisan di kota Tomohon. Di daerah ini terdapat usaha pembudidayaan bunga potong krisan yang dikelola oleh petani yang tergabung dalam kelompok tani "KIBERTA". Usaha budidaya bunga potong kelompok tani KIBERTA krisan dimulai pada tahun 2009 dan sampai sekarang kelompok tani ini memiliki empat greenhouse dan dapat memproduksi hingga 20.000 tangkai krisan dan merupakan satu dari empat kelompok tani yang dapat memproduksi terbanyak dari total 30 kelompok tani yang berada di kelurahan Kakaskasen 1. Anggota kelompok kelompok tani KIBERTA sebanyak 7 orang dengan Bapak Pungus sebagai ketua kelompok.

Tabel 1. Daftar dan Ukuran Greenhouse Kelompok Tani KIBERTA

\begin{tabular}{ccc}
\hline No. & Ukuran $\left(\mathbf{m}^{2}\right)$ & $\begin{array}{c}\text { Tahun } \\
\text { Pembangunan } \\
\text { (Tahun) }\end{array}$ \\
\hline 1 & $10 \times 25 \mathrm{~m}^{2}$ & 2012 \\
2 & $20 \times 25 \mathrm{~m}^{2}$ & 2013 \\
3 & $8 \times 14 \mathrm{~m}^{2}$ & 2014 \\
4 & $8 \times 15 \mathrm{~m}^{2}$ & 2009
\end{tabular}

Sumber : Data primer, 2016 (Diolah) 
Tabel 1 menunjukan Greenhouse milik kelompok tani KIBERTA. Budidaya bunga krisan kelompok ini dilakukan disatu Greenhouse per periode secara bergantian dengan enam minggu jarak tanam antar greenhouse dan kelompok tani ini memanen dalam tiga minggu sekali. Contoh, pada periode I misalkan kelompok tani ini menanam di Greenhouse ukuran 10 × $25 \mathrm{~m}^{2}$, setelah enam minggu kelompok tani ini menanam pada greenhouse ukuran $20 \times 25 \mathrm{~m}^{2}$ untuk periode II dan seterusnya. Sistem penanaman kelompok tani ini dilakukan agar kelompok tani KIBERTA dapat memperoleh hasil dengan berkelanjutan. Pada Greenhouse nomor 2 ukuran $20 \times 25 \mathrm{~m}^{2}$ di Tabel 1, kelompok tani ini membagi lahan menjadi dua dan digunakan untuk dua periode produksi, maka pada greenhouse ini dilakukan dua periode budidaya.

Tipe bunga krisan yang diproduksi kelompok tani ini ada dua yaitu Standar dan Spray dengan biaya dan harga yang sama per tankainya. Warna bunga krisan yang dibudidayakan untuk tipe Standar yaitu FJ Kuning, FJ Putih, Pink, Jaguar Ungu, Salju dan Jaguar Purple, sedangkan tipe Spay yaitu Aster Kuning, Aster Putih, Aster Ungu, Puma Putih, Puma Hijau, Merah dan Putih. Saluran pemasaran bunga ptong krisan kelompok tani KIBERTA adalah secara langsung, yang mana konsumen datang langsung ke greenhouse atau petani langsung mengantar jika tidak jauh dari greenhouse.

\section{Volume Panen}

Budidaya bunga potong krisan kelompok tani KIBERTA selama tiga bulan dengan sistem penanaman yang berkelanjutan serta volume produksi ditiap Greenhouse yang berbeda. Peneliti mendapati satu pohon/tanaman bunga krisan hanya dapat menghasilkan satu tangkai bunga potong, baik tipe spray atau standar maka satu tanaman krisan hanya dapat menghasilkan satu tangkai bunga potong krisan. Tabel 2 menunjukan rincian angka total panen dari total yang ditanam kelompok tani KIBERTA.
Tabel 2. Total Panen Bunga Krisan Kelompok Tani KIBERTA tiap Greenhouse.

\begin{tabular}{ccrr}
\hline No. & Ukuran $\left(\mathbf{m}^{2}\right)$ & $\begin{array}{c}\text { Total } \\
\text { Tanam } \\
\text { (tangkai) }\end{array}$ & $\begin{array}{c}\text { Total } \\
\text { Panen } \\
\text { (tangkai) }\end{array}$ \\
\hline 1 & $10 \times 25 \mathrm{~m}^{2}$ & 12.000 & 8.400 \\
2 & $20 \times 25 \mathrm{~m}^{2}$ & 24.000 & 16.800 \\
3 & $8 \times 14 \mathrm{~m}^{2}$ & 6.500 & 4.550 \\
4 & $8 \times 15 \mathrm{~m}^{2}$ & 7.500 & 5.250 \\
\hline
\end{tabular}

Sumber: Data primer, 2016 (Diolah)

Berdasarkan Tabel 2, jumlah yang dipanen/jual tidak sesuai dengan total yang ditanam, hanya $70 \%$ yang memenuhi syarat panen. Menurut hasil penelitian, 30\% dari yang ditanam memiliki kualitas buruk atau kerdil yang mana tidak bisa atau tidak memenuhi syarat panen. Total tanam dalam Tabel 2 merupakan kapasitas tanam yang dapat ditanam di greenhouse, sedangkan total panen adalah total bunga potong yang dapat dijual/panen.

\section{Harga Jual dan Penerimaan}

Penerimaan adalah hasil kali antara harga per unit dan jumlah yang diproduksi atau dalam penelitian ini dipanen. Total penerimaan dari budidaya bunga potong krisan kelompok tani KIBERTA dapat dilihat pada Table 3.

Tabel 3. Total Penerimaan Panen tiap Greenhouse

\begin{tabular}{ccccc}
\hline No. & $\begin{array}{c}\text { Ukuran } \\
\left(\mathbf{m}^{2}\right)\end{array}$ & $\begin{array}{c}\text { Total Panen } \\
(\text { tangkai })\end{array}$ & $\begin{array}{c}\text { Harga } \\
(\text { Rp/tangkai }\end{array}$ & $\begin{array}{c}\text { Total } \\
\text { Penerimaan } \\
(\mathbf{R p})\end{array}$
\end{tabular}

\begin{tabular}{ccrrr}
\hline 1 & $10 \times 25$ & 8.400 & 3.000 & 25.200 .000 \\
2 & $20 \times 25$ & 16.800 & 3.000 & 50.400 .000 \\
3 & $8 \times 14$ & 4.550 & 3.000 & 13.650 .000 \\
4 & $8 \times 15$ & 5.250 & 3.000 & 15.750 .000 \\
\hline \multicolumn{5}{l}{ Sumber: Data primer, 2016 (Diolah) }
\end{tabular}

Kelompok tani KIBERTA menjual bunga krisan dengan harga 3000/tangkai pada semua tipe dan warna. Kelompok tani KIBERTA memperoleh total penerimaan tertinggi pada Greenhouse ukuran $20 \times 25 \mathrm{~m}^{2}$, Rp. 50.400.000 yang mana sebanding dengan ukuran greenhouse. 


\section{Biaya Tetap (fixed cost)}

Biaya tetap merupakan sebagai biaya yang secara total tidak berubah ketika aktivitas bisnis meningkat atau menurun (Wijayanti, 2013). Jenis-jenis biaya tetap yang dikeluarkan oleh Kelompok Tani KIBERTA adalah biaya penyusutan peralatan, biaya penyusutan Greenhouse dan biaya sewa tanah yang dapat dilihat pada Tabel 4 berikut:

Tabel 4. Biaya Tetap tiap Greenhouse di Kelompok tani KIBERTA

\begin{tabular}{ccccc}
\hline \multirow{2}{*}{$\begin{array}{c}\text { Uraian Biaya } \\
\text { Tetap }\end{array}$} & \multicolumn{4}{c}{ Greenhouse $(\mathbf{R p})$} \\
\cline { 2 - 5 } & $\begin{array}{c}\mathbf{1} \\
(\mathbf{1 0} \times \mathbf{2 5})\end{array}$ & $\begin{array}{c}\mathbf{2} \\
\mathbf{( 2 0} \times \mathbf{2 5})\end{array}$ & $\begin{array}{c}\mathbf{3} \\
(\mathbf{8} \times \mathbf{1 4})\end{array}$ & $\begin{array}{c}\mathbf{4} \\
\mathbf{( 8 \times 1 5 )}\end{array}$ \\
\hline $\begin{array}{c}\text {-Biaya Penyusutan } \\
\text { Peralatan }\end{array}$ & $900.593,9$ & $900.593,9$ & $900.593,9$ & $900.593,9$ \\
$\begin{array}{c}\text {-Biaya Penyusutan } \\
\text { Greenhouse }\end{array}$ & 583.128 & 438.954 & 425.000 & 531.249 \\
$\begin{array}{c}\text {-Biaya Sewa Tanah } \\
\text { Total }\end{array}$ & 500.000 & 500.000 & 500.000 & 500.000 \\
\hline
\end{tabular}

Tabel 4 menunjukan bahwa biaya penyusutan peralatan adalah yang paling besar dalam biaya tetap setiap greenhouse. Uraian tiap biaya adalah sebagai berikut:

\section{a. Biaya Penyusutan Peralatan}

Biaya penyusutan dipengaruhi oleh harga beli, umur ekonomis dan nilai sisa. Dalam tabel 4. Besarnya biaya penyusutan alat dalam total biaya tetap sebesar $45,3 \%$ untuk greenhouse ukuran 10 x $25 \mathrm{~m}^{2}$, untuk greenhouse ukuran $20 \times 25 \mathrm{~m}^{2}$ sebesar $48,9 \%$, ukuran $8 \times 14 \mathrm{~m}^{2}$ sebesar $49,3 \%$ dan ukuran $8 \times 15 \mathrm{~m}^{2}$ sebesar $46.6 \%$. Dalam kegiatan budidaya bunga potong krisan dalam satu periode per greenhouse digunakan beberapa alat seperti cangkul, traktor kecil, selang, gunting, pompat semprot, dan tong/tempat penampungan air. Rincian nilai biaya penyusutan dapat dilihat pada Tabel 5.

\begin{tabular}{|c|c|c|c|c|c|c|}
\hline Jenis Alat & $\begin{array}{c}\text { Jumlah } \\
\text { (Unit) }\end{array}$ & $\begin{array}{c}\text { Harga Beli } \\
\text { (Rp/Unit) }\end{array}$ & $\begin{array}{c}\text { Umur } \\
\text { Ekono } \\
\text { mis } \\
\text { (Tahun } \\
\text { ) }\end{array}$ & $\begin{array}{l}\text { Nilai Sisa } \\
\text { (Rp) }\end{array}$ & $\begin{array}{c}\text { Penyusutan } \\
\text { (Rp per } \\
\text { Tahun) }\end{array}$ & $\begin{array}{c}\text { Total } \\
\text { Penyusutan } \\
\text { (Rp/Periode } \\
\text { ) }\end{array}$ \\
\hline Cangkul & 2 & 60.000 & 2 & 9.000 & 25.500 & 531,3 \\
\hline $\begin{array}{l}\text { Traktor } \\
\text { Kecil }\end{array}$ & 1 & 15.000 .000 & 10 & 2.250 .000 & 1.275 .000 & 318.750 \\
\hline Selang & 1 & 550.000 & 5 & 82.500 & 93.500 & 23.375 \\
\hline Gunting & 4 & 45.000 & 3 & 6.750 & 12.750 & 3.079 \\
\hline $\begin{array}{l}\text { Pompa } \\
\text { Semprot }\end{array}$ & 1 & 750.000 & 10 & 112.500 & 63.750 & $6.640,6$ \\
\hline Tong & 1 & 1.250 .000 & 8 & 187.000 & 132.875 & 33.218 \\
\hline $\begin{array}{l}\text { Motor } \\
\text { Roda } \\
\text { Tiga }\end{array}$ & 1 & 20.800 .000 & 8 & 4.320 .000 & 2.060 .000 & 515.000 \\
\hline \multicolumn{6}{|c|}{ Total } & 900.593, \\
\hline
\end{tabular}

Sumber: Data primer, 2016 (Diolah)
Jenis alat yang digunakan dalam budidaya bunga potong krisan dalam satu kali periode produksi dapat dilihat pada tabel 5 . Total penyusutan diperoleh dari nilai penyusutan lalu dibagi jumlah bulan per tahun yaitu 12, dibagi total minggu per bulan yaitu 4 dan dikali total pakai dalam minggu untuk satu kali periode produksi dan dikali jumlah unit peralatan yang digunakan. Alat yang memiliki proporsi lama pemakaian kurang dari 3 bulan yaitu cangkul, gunting dan pompa semprot, sedangkan yang lain digolongkan digunakan selama 3 bulan penuh. Untuk cangkul hanya digunakan pada masa penggarapan lahan yaitu selama 1 minggu, gunting digunakan selama 3 minggu dalam masa disbunding dan pemanenan, dan pompa semprot digunakan selama 5 minggu yaitu pada masa penyemprotan hama bunga.

\section{b. Biaya Penyusutan Greenhouse}

Besarnya biaya penyusutan greenhouse dalam biaya tetap sebesar 29,3\% untuk greenhouse ukuran 10 x $25 \mathrm{~m}^{2}$, untuk greenhouse ukuran $20 \times 25 \mathrm{~m}^{2}$ sebesar $23,8 \%$, ukuran $8 \times 14 \mathrm{~m}^{2}$ sebesar $23,2 \%$ dan ukuran 8 x $15 \mathrm{~m}^{2}$ sebesar $27,4 \%$. Kelompok tani KIBERTA memiliki empat greenhouse yang dengan ukuran dan bahan baku pembuatan berbeda yang digunakan dalam budidaya bunga potong krisan. Biaya penyusutan greenhouse tersebut dipengaruhi oleh biaya pembuatan, umur ekonomis dan nilai sisa yang dapat dilihat pada Tabel 6 berikut.

\begin{tabular}{|c|c|c|c|c|c|}
\hline $\begin{array}{c}\text { Ukuran } \\
\left(\mathbf{m}^{2}\right)\end{array}$ & $\begin{array}{c}\text { Biaya } \\
\text { Pembuatan } \\
\text { (Rp) }\end{array}$ & $\begin{array}{c}\text { Umur } \\
\text { Ekonomis } \\
\text { (Tahun) }\end{array}$ & $\begin{array}{l}\text { Nilai Sisa } \\
\text { (Rp) }\end{array}$ & $\begin{array}{l}\text { Penyusutan } \\
\text { (Rp/Tahun) }\end{array}$ & $\begin{array}{c}\text { Penyusutan } \\
\text { (Rp/Periode) }\end{array}$ \\
\hline $\begin{array}{l}10 \times 25 \\
\mathrm{~m}^{2}\end{array}$ & 41.162 .000 & 15 & 6.174 .300 & 2.323 .513 & 583.128 \\
\hline $\begin{array}{l}20 \times 25 \\
\mathrm{~m}^{2}\end{array}$ & 30.985 .000 & 10 & 4.647 .750 & 1.755 .816 & 438.954 \\
\hline $\begin{array}{l}8 \times 14 \\
m^{2}\end{array}$ & 60.000 .000 & 30 & 9.000 .000 & 1.700 .000 & 425.000 \\
\hline $\begin{array}{l}8 \times 15 \\
m^{2}\end{array}$ & 25.000 .000 & 10 & 3.750 .000 & 2.125 .000 & 531.249 \\
\hline \multicolumn{5}{|c|}{ Total } & 1.978 .331 \\
\hline
\end{tabular}

Ketidaksesuaian biaya pembuatan greenhouse dengan ukuran dan umur ekonomis yang bervariasi dikarenakan oleh bahan baku/kerangka greenhouse yang berbeda dalam pembuatan. Pada greenhouse ukuran $10 \times 25 \mathrm{~m}^{2}$ kerangka yang digunakan adalah kayu, yang 
mana kayu ini merupakan kayu khusus lebih lama lapuk serta tidak mudah terserang rayap oleh karena itu memiliki umur ekonomis yang relatiF tinggi. Sedangkan pada greenhouse ukuran $20 \times 25 \mathrm{~m}^{2}$ dan $8 \times 15 \mathrm{~m}^{2}$ menggunakan kerangka bambu, yang mana bamboo ini lebih pendek umur ekonomisnya. Pada greenhouse ukuran $8 \times 14 \mathrm{~m}^{2}$ menggunakan kerangka baja ringan, lebih mahal akan tetapi memiliki umur ekonomis yang sangat tinggi dibandingkan dengan greenhouse dengan kerangka selain baja.

\section{c. Biaya sewa tanah}

Besarnya sewa tanah dalam biaya tetap sebesar 25,2\% untuk greenhouse ukuran $10 \mathrm{x}$ $25 \mathrm{~m}^{2}$, untuk greenhouse ukuran $20 \times 25 \mathrm{~m}^{2}$ sebesar $27,1 \%$, ukuran $8 \times 14 \mathrm{~m}^{2}$ sebesar 27,3 $\%$ dan ukuran $8 \times 15 \mathrm{~m}^{2}$ sebesar $28,8 \%$. Dalam penelitian ini beban sewa tanah yang harus dikeluarkan untuk membayar sewa tanah setiap satu kali periode tanam yang digunakan kemlompok tani KIBERTA. Tanah yang disewa oleh kelompok tani ini seluas 2 ha. Beban sewa per hektar sebesar Rp.1.000.000,- per tahun dan biaya yang harus dibayarkan tiap 3 bulan atau periode adalah sebesar Rp.500.000,merupakan hasil pembagian dari Beban Sewa Per Tahun dan 12 bulan lalu dikali tiga bulan.

\section{Biaya Variabel (Variable Cost)}

Biaya variable adalah biaya yang totalnya meningkat secara proporsional terhadap peningkatan dalam aktivitas dan menurun secara proporsional terhadap penurunan dalam aktivitas (Wijayanti, 2013). Biaya variabel dalam penelitian ini merupakan biaya yang dibayarkan untuk budidaya bunga potong krisan per greenhouse yaitu biaya bahan baku, biaya bahan bakar, dan biaya tenaga kerja yang dapat dilijat pada Tabel 7 berikut:

\begin{tabular}{|c|c|c|c|c|}
\hline \multirow[b]{2}{*}{ Uraian Biaya Variabel } & \multicolumn{4}{|c|}{ Greenhouse (Rp) } \\
\hline & $\begin{array}{c}1 \\
(10 \times 25) \\
\end{array}$ & $\begin{array}{c}2 \\
(20 \times 25) \\
(20\end{array}$ & $\begin{array}{c}3 \\
(8 \times 14)\end{array}$ & $\begin{array}{c}4 \\
(8 \times 15) \\
\end{array}$ \\
\hline -Biaya Bibit & 6.000 .000 & 12.000 .000 & $\begin{array}{r}3.250 .00 \\
0\end{array}$ & $\begin{array}{r}3.750 .00 \\
0\end{array}$ \\
\hline -Biaya Pembasmi Hama & 107.000 & 214.000 & 49.700 & 57.200 \\
\hline -Biaya Pupuk & 1.247 .000 & 2.494.000 & 580.000 & 667.000 \\
\hline -Biaya Listrik & 150.000 & 300.000 & 67.700 & 80.000 \\
\hline $\begin{array}{l}\text {-Biaya Bahan Bakar } \\
\text {-Biaya Tenaga Kerja }\end{array}$ & $\begin{array}{l}79.350 \\
1.000 .000\end{array}$ & $\begin{array}{r}98.700 \\
1.800 .000\end{array}$ & $\begin{array}{r}69.675 \\
400.000\end{array}$ & $\begin{array}{r}69.675 \\
400.000\end{array}$ \\
\hline Total & 8.583.850 & 16.907 .700 & $\begin{array}{r}4.419 .07 \\
5\end{array}$ & $\begin{array}{r}5.023 .87 \\
5\end{array}$ \\
\hline
\end{tabular}

Tabel 7 menunjukan bahwa biaya bibit adalah yang paling besar dalam biaya variabel setiap greenhouse. Uraian tiap biaya dan persentase adalah sebagai berikut:

\section{a. Biaya Bibit}

Besarnya biaya bibit dalam biaya variabel sebesar $69.0 \%$ untuk greenhouse ukuran $10 \times 25 \mathrm{~m}^{2}$, untuk greenhouse ukuran 20 x $25 \mathrm{~m}^{2}$ sebesar $71 \%$, ukuran $8 \times 14 \mathrm{~m}^{2}$ sebesar $73,5 \%$ dan ukuran $8 \times 15 \mathrm{~m}^{2}$ sebesar 74,6\%. Bibit krisan diperoleh dari pasar bibit krisan yang berlokasi di Surabaya Jawa Timur, karena pembibit lokal tidak dapat memenuhi pemintaan yang besar dan tidak selalu tersedia. Harga per bibitnya Rp. 500,- untuk semua tipe dan warna.

\section{b. Biaya Pembasmi Hama}

Besarnya biaya pembasmi hama dalam biaya biaya variabel sebesar $1,2 \%$ untuk greenhouse ukuran $10 \times 25 \mathrm{~m}^{2}$, untuk greenhouse ukuran $20 \times 25 \mathrm{~m}^{2}$ sebesar $1,3 \%$, ukuran $8 \times 14 \mathrm{~m}^{2}$ sebesar $1,1 \%$ dan ukuran $8 \times$ $15 \mathrm{~m}^{2}$ sebesar $1,1 \%$.

\section{c. Biaya Pupuk}

Besarnya biaya pupuk dalam biaya variabel sebesar $14,5 \%$ untuk greenhouse ukuran $10 \times 25 \mathrm{~m}^{2}$, untuk greenhouse ukuran 20 x $25 \mathrm{~m}^{2}$ sebesar $14,8 \%$, ukuran 8 x $14 \mathrm{~m}^{2}$ sebesar $13,1 \%$ dan ukuran $8 \times 15 \mathrm{~m}^{2}$ sebesar $13,3 \%$.

\section{d. Biaya Listrik}

Besarnya biaya listrik dalam biaya variabel sebesar $1,7 \%$ untuk greenhouse ukuran $10 \times 25 \mathrm{~m}^{2}$, untuk greenhouse ukuran 20 x $25 \mathrm{~m}^{2}$ sebesar $1,8 \%$, ukuran $8 \times 14 \mathrm{~m}^{2}$ sebesar $1,5 \%$ dan ukuran $8 \times 15 \mathrm{~m}^{2}$ sebesar 1,6 $\%$. Biaya listrik dalam penelitian ini dikeluarkan untuk penyinaran. Penggunaan listrik untuk masing-masing greenhouse berbeda tergantung pada besar dan luas greenhouse yang digunakan.

\section{e. Biaya Bahan Bakar}

Besarnya biaya bahan bakar dalam biaya variabel sebesar 0,9\% untuk greenhouse ukuran $10 \times 25 \mathrm{~m}^{2}$, untuk greenhouse ukuran 20 x $25 \mathrm{~m}^{2}$ sebesar $0,6 \%$, ukuran $8 \times 14 \mathrm{~m}^{2}$ sebesar 1,6\% dan ukuran $8 \times 15 \mathrm{~m}^{2}$ sebesar 1,4 $\%$. 
Biaya bahan bakar dalam penelitian ini adalah biaya yang dikeluarkan untuk bahan bakar Traktor kecil dan Motor roda tiga. Penggunaan Traktor kecil untuk penggarapan tanah ketika akan dilakukan penanaman sedangkan Motor tiga roda untuk pengankutan tenaga kerja, bibit, dan pesanan jarak tak terlalu jauh. Peneliti membagi biaya bahan bakar yang digunakan per greenhouse dalam satu periode yang dapat dilihat pada Tabel 8 .

\begin{tabular}{|c|c|c|c|c|}
\hline \multirow[b]{2}{*}{ Jenis Alat } & \multicolumn{4}{|c|}{ Greenhouse (Rp) } \\
\hline & $\begin{array}{c}1 \\
(10 \times 25) \\
\end{array}$ & $\begin{array}{c}2 \\
(20 \times 25) \\
\end{array}$ & $\begin{array}{c}3 \\
(8 \times 14) \\
\end{array}$ & $\begin{array}{c}4 \\
(8 \times 15) \\
\end{array}$ \\
\hline Traktor Kecil & 19.350 & 38.700 & 9.675 & 9.675 \\
\hline Motor Tiga Roda & 60.000 & 60.000 & 60.000 & 60.000 \\
\hline Total & 79.350 & 98.700 & 69.675 & 69.675 \\
\hline
\end{tabular}

Harga bahan bakar yang digunakan di tabel 8 adalah Rp. 6450,- per liter. Biaya tumpuan yang gunakan kelompok tani ini dalam penentuan biaya bahan bakar traktor kecil adalah biaya greenhouse ukuran $10 \times 25$. Luas greenhouse ukuran $20 \times 25$ dua kali lebih besar maka biaya garapan dua kali lebih besar dari greenhouse ukuran $10 \times 25$. Biaya greenhouse ukuran $8 \times 14$ dan $8 \times 15$ adalah setengah dari biaya greenhouse ukuran 10 x 25 , yang dikarenakan luas lahan yang dapat digarap dengan setengah bahan bakar dari greenhouse ukuran $10 \times 25$.

\section{f. Biaya Tenaga Kerja}

Besarnya biaya bahan bakar dalam biaya variabel sebesar 11,6\% untuk greenhouse ukuran $10 \times 25 \mathrm{~m}^{2}$, untuk greenhouse ukuran 20 x $25 \mathrm{~m}^{2}$ sebesar 10,6\%, ukuran 8 x $14 \mathrm{~m}^{2}$ sebesar 9,1\% dan ukuran $8 \times 15 \mathrm{~m}^{2}$ sebesar 8,0 $\%$. Rincian biaya tenaga kerja yang digunakan per greenhouse dalam satu periode yang dapat dilihat pada Tabel 9.

\begin{tabular}{|c|c|c|c|c|c|}
\hline $\begin{array}{c}\text { Ukuran } \\
\text { Greenhous } \\
e \\
\left(\mathbf{m}^{2}\right) \\
\end{array}$ & Uraian Kegiatan & $\begin{array}{c}\text { Jumlah } \\
\text { Tenaga } \\
\text { Kerja } \\
\text { (Orang) } \\
\end{array}$ & $\begin{array}{l}\text { Jum } \\
\text { lah } \\
\text { Hari }\end{array}$ & $\begin{array}{l}\text { Upah } \\
\text { (Rp) }\end{array}$ & $\begin{array}{l}\text { Total Upah } \\
\text { (Rp) }\end{array}$ \\
\hline \multirow{3}{*}{$10 \times 25$} & a. Penggarapan & 1 & 1 & 100.000 & \multirow{4}{*}{1.000 .000} \\
\hline & b. Penanaman & 2 & 1 & 200.000 & \\
\hline & c. Pemupukan & 1 & 1 & 100.000 & \\
\hline \multirow{5}{*}{$20 \times 25$} & d. Pemeliharaan & 2 & 3 & 600.000 & \\
\hline & a. Penggarapan & 1 & 1 & 100.000 & \multirow{4}{*}{1.800 .000} \\
\hline & b. Penanaman & 4 & 1 & 400.000 & \\
\hline & c. Pemupukan & 1 & 1 & 100.000 & \\
\hline & d. Pemeliharaan & 4 & 3 & 1.200 .000 & \\
\hline \multirow{4}{*}{$8 \times 14$} & a. Penggarapan & 1 & 1 & 100.000 & \multirow{4}{*}{400.000} \\
\hline & b. Penanaman & 1 & 1 & 100.000 & \\
\hline & c. Pemupukan & 1 & 1 & 100.000 & \\
\hline & d. Pemeliharaan & 1 & 1 & 100.000 & \\
\hline \multirow{4}{*}{$8 \times 15$} & a. Penggarapan & 1 & 1 & 100.000 & \multirow{4}{*}{400.000} \\
\hline & b. Penanaman & 1 & 1 & 100.000 & \\
\hline & c. Pemupukan & 1 & 1 & 100.000 & \\
\hline & d. Pemeliharaan & 1 & 1 & 100.000 & \\
\hline
\end{tabular}

Biaya tenaga kerja dalam penelitian ini adalah biaya yang dikeluarkan untuk membayar tenaga kerja dalam budidaya bunga potong krisan. Tenaga kerja yang diperkerjakan untuk kegiatan pengelolahan lahan, penanaman, pemupukan, dan pemeliharaan.

Upah tenaga kerja sebesar Rp.100.000,per orang per hari. Total upah diperoleh dari hasil penjumlahan nilai upah. Kelompok tani KIBERTA memperkerjakan orang tambahan terbanyak pada penanaman dan pemeliharaan, terutama pada pemeliharaan karna perlu pembersihan menyeluruh pada tiap pohon. Sedangkan pada kegiatan penggarapan dan pemupukan membutuhkan tenaga kerja tambahan terkecil.

\section{Analisis Break Even Point (BEP)}

Berdasarkan data penerimaan, harga dan total panen tiap ukuran greenhouse dan biaya kedalam biaya tetap dan veriabel, dapat dihitung break even point dan keuntungan dari budidaya bunga potong krisan kelompok tani KIBERTA pada masing-masing greenhouse. Perhitungan break even point untuk masingmasing greenhouse pada satu priode panen dapat dilihat pada Tabel 10 .

Tabel 10. Rekapitulasi Break Even Point dan Keuntungan Budidaya Bunga Potong Krisan Kelompok Tani KIBERTA

\begin{tabular}{|c|c|c|c|c|}
\hline \multirow{2}{*}{ Uraian } & \multicolumn{4}{|c|}{ Greenhouse (Rp) } \\
\hline & $\begin{array}{c}1 \\
(10 \times 25)\end{array}$ & $\begin{array}{c}2 \\
(20 \times 25)\end{array}$ & $\begin{array}{c}3 \\
(8 \times 14)\end{array}$ & $\begin{array}{c}4 \\
(8 \times 15)\end{array}$ \\
\hline -Biaya Tetap & 1.983 .722 & 1.839 .548 & $\begin{array}{r}1.825 .59 \\
4\end{array}$ & $\begin{array}{r}1.931 .84 \\
3\end{array}$ \\
\hline -Biaya Variabel & 8.583 .850 & 16.907 .700 & $\begin{array}{r}4.419 .07 \\
5\end{array}$ & $\begin{array}{r}5.023 .87 \\
5\end{array}$ \\
\hline -Biaya Variabel per unit & 1.022 & 1.006 & 971 & 957 \\
\hline -Harga per tangkai & 3.000 & 3.000 & 3.000 & 3.000 \\
\hline -Total Produksi & 8.400 & 16.800 & 4.550 & 5.250 \\
\hline -Penerimaan & 25.200 .000 & 50.400 .000 & $\begin{array}{r}13.650 .0 \\
00\end{array}$ & $\begin{array}{r}15.750 .0 \\
00\end{array}$ \\
\hline$\overline{\text { BEP (Penerimaan) }}$ & $3.008 .678,5$ & $2.767 .624,9$ & $\begin{array}{r}2.699 .25 \\
1,8\end{array}$ & $\begin{array}{r}2.836 .77 \\
3,9\end{array}$ \\
\hline$\overline{\text { BEP (Unit) }}$ & $1.002,9$ & 922,5 & 899,8 & 945,6 \\
\hline Keuntungan & $22.191 .321,5$ & 47.632.375,1 & $\begin{array}{r}10.950 .7 \\
48,2\end{array}$ & $\begin{array}{r}12.913 .2 \\
26,1\end{array}$ \\
\hline
\end{tabular}

Tabel 10 mennujukan hasil perhitungan break even point atas dasar rupiah dan unit. Berdasarkan hasil analisis pada tabel 11 dapat diketahui bahwa Budidaya Bunga Potong Krisan Kelompok Tani KIBERTA dari sisi penerimaan dan produksinya telah melampaui break even point disemua greenhouse. Keuntungan secara berurut dari terbesar diperoleh 
greenhouse ukuran $20 \times 25 \mathrm{~m}^{2}$ yang mana memiliki ukuran terbesar sebesar Rp. 47.632.375,1 lalu kedua dari green house ukuran 10 × $25 \mathrm{~m}^{2}$ sebesar Rp. 22.191.321,5 pada ukuran green house $8 \times 15 \mathrm{~m}^{2}$ keuntungan sebesar Rp. 12.913.226,1 dan 8 x $14 \mathrm{~m}^{2}$ sebesar Rp. 10.950.748,2. Dengan demikian kelompok tani KIBERTA telah dapat memperoleh keuntungan dari usaha budidaya bunga potong krisan pada setiap greenhouse.

Berikut adalah grafik break even point budidaya bunga potong krisan kelompok tani KIBERTA pada masing-masing green house ukuran $10 \times 25 \mathrm{~m}^{2}, 20 \times 25 \mathrm{~m}^{2}, 8 \times 14 \mathrm{~m}^{2}$, dan $8 \times 15 \mathrm{~m}^{2}$. Greenhouse ukuran $10 \times 25 \mathrm{~m}^{2}$ telah melampaui break even point yang tersaji pada grafik Break Even Point Budidaya Bunga Potong Krisan Greenhouse ukuran 10 x $25 \mathrm{~m}^{2}$ sebagai berikut:

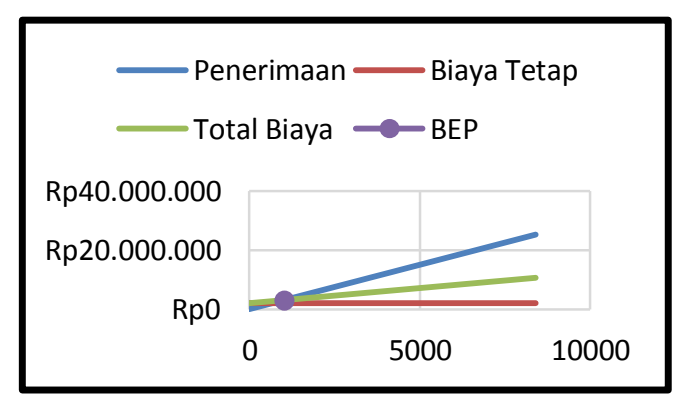

Gambar 3. Grafik Break Even Point Budidaya Bunga Potong Krisan Greenhouse ukuran $10 \mathrm{x}$ $25 \mathrm{~m}^{2}$

Berdasarkan grafik pada gambar 3, kondisi impas/BEP terjadi pada saat penerimaan sebesar Rp. 3.008.678,5 dan produksi 1.002,9 tangkai dan dapat dilihat bahwa kelompok tani ini berada diatas titik break even dengan kata lain budidaya bunga potong krisan kelompok tani KIBERTA pada greenhouse ukuran 10 x $25 \mathrm{~m}^{2}$ telah melampui break even point dan dapat memperoleh keuntungan. Greenhouse ukuran $20 \times 25 \mathrm{~m}^{2}$ telah melampaui break even point yang tersaji pada grafik Break Even Point Budidaya Bunga Potong Krisan Greenhouse ukuran $20 \times 25 \mathrm{~m}^{2}$ sebagai berikut:

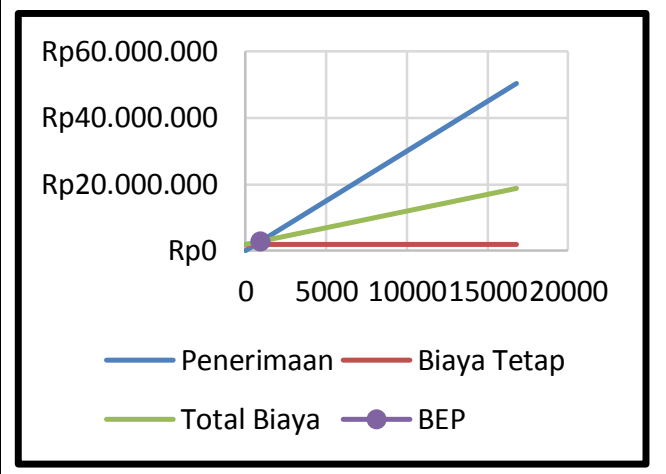

Gambar 4. Grafik Break Even Point Budidaya Bunga Potong Krisan Greenhouse ukuran 20 x $25 \mathrm{~m}^{2}$

Berdasarkan grafik pada gambar 4, kondisi impas/BEP terjadi pada saat penerimaan sebesar Rp. 2.767.624,9 dan produksi 922,5 tangkai dan dapat dilihat bahwa kelompok tani ini berada diatas titik break even dengan kata lain budidaya bunga potong krisan kelompok tani KIBERTA pada greenhouse ukuran $20 \quad$ x $25 \quad \mathrm{~m} 2$ telah melampui break even point dan dapat memperoleh keuntungan. Greenhouse ukuran $10 \times 25 \mathrm{~m}^{2}$ telah melampaui break even point yang tersaji pada grafik Break Even Point Budidaya Bunga Potong Krisan Greenhouse ukuran 8 x $14 \mathrm{~m}^{2}$ sebagai berikut:

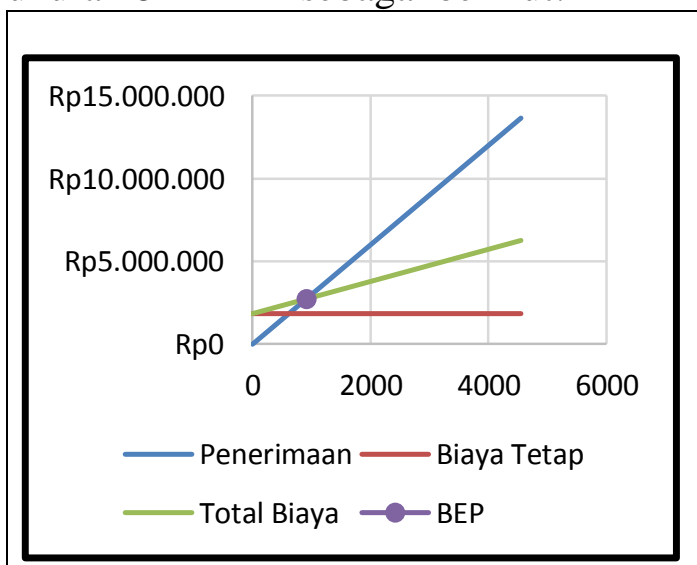

Gambar 5. Grafik Break Even Point Budidaya Bunga Potong Krisan Greenhouse ukuran 8 x $14 \mathrm{~m}^{2}$

Berdasarkan grafik pada gambar 5, kondisi impas/BEP terjadi pada saat penerimaan sebesar Rp. 2.699.251,8 dan produksi 899,8 tangkai dan dapat dilihat bahwa kelompok tani ini berada diatas titik break even dengan kata lain budidaya bunga potong krisan kelompok tani KIBERTA pada greenhouse ukuran $8 \times 14 \mathrm{~m}^{2}$ telah melampui break even point dan dapat memperoleh 
keuntungan. Greenhouse ukuran $10 \times 25 \mathrm{~m}^{2}$ telah melampaui break even point yang tersaji pada grafik Break Even Point Budidaya Bunga Potong Krisan Greenhouse ukuran 10 x $25 \mathrm{~m}^{2}$ sebagai berikut:

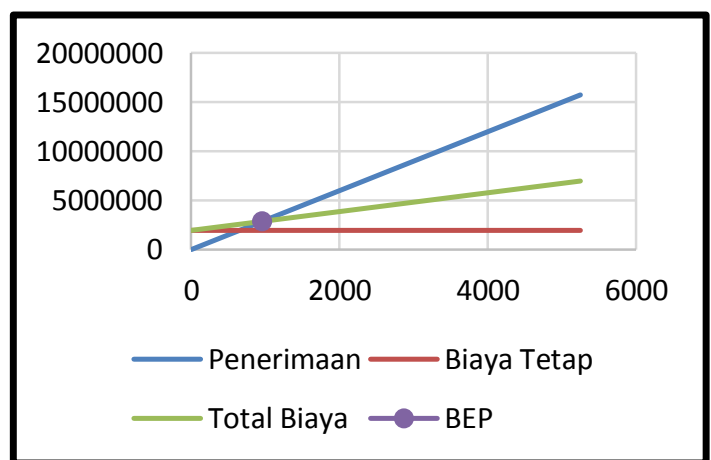

Gambar 6. Grafik Break Even Point Budidaya Bunga Potong Krisan Greenhouse ukuran 8 x $15 \mathrm{~m}^{2}$

Berdasarkan grafik pada gambar 6, kondisi impas/BEP terjadi pada saat penerimaan sebesar Rp. 2.836.773,9 dan produksi 945,6 tangkai dan dapat dilihat bahwa kelompok tani ini berada diatas titik break even dengan kata lain budidaya bunga potong krisan kelompok tani KIBERTA pada greenhouse ukuran $8 \times 15 \mathrm{~m}^{2}$ telah melampui break even point dan dapat memperoleh keuntungan.

Grafik-grafik diatas dapat diketahui bahwa titik break even point adalah titik pertemuan antara garis biaya total dengan garis total penerimaan, dari grafik tersebut dapat diketahui pula bahwa saat terjadi break even point maka keuntungan atau profit yang didapat perusahaan sama dengan nol. Semakin kecil BEP maka semakin mudah suatu usaha dapat memperoleh keuntungan. Hasil analisis menunjukan budidaya bunga potong krisan kelompok tani KIBERTA memiliki nilai BEP kecil karena biaya yang digunakan kecil, terutama biaya tetap. Semakin kecil biaya tetap semakin mudah suatu usaha memproduksi dalam kapasitas besar, karena biaya tetap tidak akan berubah.

\section{KESIMPULAN DAN SARAN}

\section{Kesimpulan}

Berdasarkan hasil analisis data Budidaya bunga potong krisan pada kelompok tani KIBERTA kelurahan Kakaskasen 1 Kota Tomohon diperoleh kesimpulan Budidaya bunga potong krisan pada kelompok tani ini sebagai berikut:

1. Dari $100 \%$ yang ditanam hanya $70 \%$ yang memenuhi syarat panen dan jual.

2. Budidaya bunga potong krisan pada kelompok tani KIBERTA telah melampaui Break Even Point atau titik impas baik produksi maupun penerimaan dan dapat memperoleh keuntungan pada semua greenhouse.

\section{Saran}

Kelompok tani KIBERTA dalam budidaya bunga potong krisan ini memiliki biaya tetap kecil sehingga peningkatan usaha harus dilakukan agar dapat meningkatkan kapasitas produksi dan keuntungan.

\section{DAFTAR PUSTAKA}

Alaika Royhan, 2011. Klasifikasi Bunga Krisan (CRHYSANTIMUM). academia.edu. 16 Juni 2016

Astuti Aini, 2010. Analisis Efektifitas Kelompok Tani Kelompok Tani di Kecamatan Gatak Kabupaten Sukoharjo. Universitas Sebelas Maret. Surakarta. Jurnal.12 Juni 2016

Bawinto Alvianti, 2016. Analisis Break even point Ternak Sapi Potong Kelompok Tani "Sumber Hidup Sejati” Di Kecamatan Bintauna Kabupaten Bolaang Mongondow Utara. Universitas Sam Ratulangi. Manado. Jurnal. 9 Juni 2016 
Butaflika, 2008. Analisis Kelayakan Perencanaan Program Pengusahaan Krisan Di Kabupaten Lampung Barat. Institut Pertanian Bogor. Bogor. Jurnal. 11 Juni 2016.

Hermanto, 2011. Penguatan Kelompok Tani: Langkah Awal Peningkatan Kesejahteraan Petani. Pusat Sosial Ekonomi dan Kebijakan Pertanian. Bogor. Jurnal. 12 Juni 2016

Hutani Sulina Surika, 2015. Analisis Break even point Pada Usaha Kerupuk Singkong UD Kelompok Tani Kulim Unggul Kelurahan Kulim Kota Pekanbaru. Universitas Riau. Pekanbaru. Jurnal. 15 Juni 2016.

Institut Pertanian Bogor, 2011. II TINJAUAN PUSTAKA. http:// repository. ipb.ac.id/. 11 Juni 2016.

Munawir S, 2002. Analisis Break Even Point. Scribd.com. 1 Agustus 2016

Nuraga, M. R, 2015. Evaluasi Tarif Berdasarkan Biaya Operasional Kendaraan (Bok), Ability To Pay (Atp), Willingness To Pay (Wtp), Dan Analisis Break Even Point (Bep) Bus Batik Solo Trans (Bst)(Studi Kasus: Koridor 7). Doctoral dissertation, Universitas Sebelas Maret. Jurnal. 28 Juni 2016

Pagemanan L, 2011. Analisis Pendapatan Usaha Tani Bunga Potong (Studi Kasus Petani Bunga Krisan Putih Di Kelurahan Kakaskasen Dua Kecamatan Tomohon Utara Kota Tomohon). ASE - Volume 7 Nomor 2. Tomohon. Jurnal. 29 Juni 2016.
Puspitasari Iva, 2009. Budidaya Bunga Potong Krisan (Chysathenum sp.) Di Kelompok Tani Uni Makmur Wonokerso Hargobinangun, Pakem, Sleman. Universitas Sebelas Maret. Surakarta. Jurnal. 14 Juni 2016.

Raharjo Guntur, 2014. Bauran Pemasaran Bunga Krisan Pada Kelompok Tani Sahabattani Di Kelurahan Kakaskasen Dua Kecamatan Tomohon Utarakota Tomohon. Univesitas Sam Ratulangi. Manado. Jurnal. 29 Juni 2016

Rakhimawati Dewi, 2008. Analisis Break even point Pada Usaha Pengelolahan Pucuk Daun Teh(Kasus Di Pabrik Teh Sumber Daun Kabupaten Cianjur). Universitas Sebelas Maret. Surakarta. Jurnal. 12 Juni 2016.

Samryn LM, 2012. Akutansi Manajemen Informasi Biaya Untuk Mengendalikan Aktivitas Operasi Dan Informasi. Kencana. Jakarta.

Setyanti Axellita, 2016. Analisis Produksi dan Efesiensi Usahatani Bunga Potong (Studi Pada Desa Gunung Sari, Kecamatan Bumiaji, Kota Batu) Universitas Brawijaya. Malang. Jurnal. 10 Juni 2016.

Sumarno Gilang Dwi, 2009. Kelayakan Usaha Budidaya Bunga Krisam Petani Anggota Asosiasi Tanaman Hias Bunga dan Daun Dikecamatan Pakem Kabupaten Sleman. Universitas Muhammadiyah Yogyakarta. Yogyakarta. Jurnal. 10 Juni 2016. 
Universitas Sumatera Utara, 2012, BAB II TINJAUAN PUSTAKA. https://www.google.com. 28 Juni 2016
Wijayanti Suci, 2013. Analisis Break even point Sebagai Salah Satu Alat Perencanaan Penjualan Dan Keuntungan. Universitas Brawijaya. Malang. Jurnal. 12 Juni 2016. 